EPiC Series in Engineering
Volume 3, 2018, Pages 1415-1423
HIC 2018. 13th International
Conference on Hydroinformatics

\title{
Z-R law for quantitative rainfall estimation using a C-band radar and a network of ground- based disdrometers
}

\author{
Roberta Karinne Mocva-Kurek ${ }^{1,2}$ and Adrián Pedrozo-Acuña ${ }^{1}$ \\ ${ }^{1}$ Instituto de Ingeniería, Universidad Nacional Autónoma de México \\ ${ }^{2}$ Programa de Maestría y Doctorado en Ingeniería, Universidad Nacional Autónoma de México \\ rkurekm@ii.unam.mx, apreozoadii.unam.mx
}

\begin{abstract}
It is acknowledged that spatial variations in the DSD and type of rainfall are important for an adequate rainfall estimation using operational weather radars. However, due to a lack of instrumentation, the Z-R relationship is rarely considered spatially variable. This relationship is usually applied unawarely of the scale, which is questionable since the nonlinearity of this relation could lead to undesirable discrepancies when combined with scale aggregation. This paper investigates different methods to define an adequate $\mathrm{Z}-\mathrm{R}$ law relation for a study region, where a spatial variation of coefficients and rain type may be considered. For this, we utilize data from a disdrometers network and a C-band radar located in Mexico City. Coefficients of the Z-R law are obtained through: the definition of the Z-R relationship at each disdrometer and the use of three methods (dBZ, R and $\mathrm{Do} / \mathrm{R}$ ) for the data classification by rain type (ST, T, C). Results show that the coefficients for the Z-R law are very diverse and strongly dependent on the rain type. Regarding radar data, the evaluation indicates that the values do not correspond quantitatively to those recorded on the earth's surface, but it can represent the variances in most of the period.
\end{abstract}

\section{Introduction}

A weather radar is an effective tool for rainfall estimation, it provides a very useful characterization of the spatial and temporal distribution of storms, which are required in many urban hydrological studies [1]. For example, [2] recommended resolutions of about $3 \mathrm{~km}$ in space and $5 \mathrm{~min}$ in time for urban catchments. These requirements make of the weather radar a key component to provide short-term precipitation measurements and forecasts; moreover, this is more important in urban environments, which are dominated by convective storms [3]. Indeed, the usually used rain gauge data does not allow for the data acquisition at the required resolutions for this type of studies [4]. 
Commonly, the rainfall estimation from weather radar is based on empirical models such as reflectivity-rain rate (Z-R) power-law relation, i.e., $Z=a^{*} R^{\wedge} b$. However, these equations are generally used while unaware of the scale, which is questionable since the nonlinearity of these relations could lead to large uncertainties. In the original study by Marshall and Palmer [5], the coefficients were determined to be $a=200$ and $b=1.6$. Since the coefficients $(a, b)$ are related with drop size distribution (DSD) properties, they are frequently derived at a point scale, not at radar scale, which could lead to errors at the latter. Furthermore, it is acknowledged that specific values of the coefficients may vary in relation to the geographical location, the climate, and consequently the type of rainfall that is measured. With this in mind, there have been studies that demonstrated a distinction between convective and stratiform in regions of tropical rain [6]. Despite this, the use of Z-R laws for estimating rainfall remains subject to many uncertainties. Numerous studies have been carried out to estimate the coefficients a and $\mathrm{b}$ which were found to vary in a large range of values: 30-1000 and 0.8-2 [e.g. 7, 8].

Recently, the development of instruments, such as the laser optical disdrometers, provide new insights on the actual DSD relationship at a point scale, which enable a better estimation of the coefficients that are used in Z-R relationships. However, it is not common to have a worldwide network of disdrometers that enable a spatial characterization of this relationship at the catchment scale.

On the other hand, in Mexico City, the National Weather Service has a C-band radar that is used for the follow-up of storms, however the lack of Z-R relations for this instrument limits its usability to derive accurate rainfall. Recently, the Institute of Engineering of the National Autonomous University of Mexico (IIUNAM), installed a ground-based network to measure rainfall which is comprised by 10 disdrometers within the coverage area of the $\mathrm{C}$-band radar. This network enables a careful investigation of the definition of the coefficients utilized in the Z-R relationship of this radar.

Therefore, the purpose of this paper is to investigate the effects of scale and rainfall type in the definition of coefficients $(a, b)$ within a catchment and the use these coefficients for the quantitative estimation of rainfall with radar data. This will enable a careful study on how to determine an adequate $\mathrm{Z}-\mathrm{R}$ law relation for this region and will provide an insight on how to reduce known uncertainties ascribed to relation. These coefficients are obtained through: (1) the definition of the Z-R relationship at each disdrometer and (2) the use of three methods (dBZ, R and Do/R) for the data classification by rain type (stratiform, transition rain or convective). Indeed, the use of this network of disdrometers paves the road towards answering key questions in the implementation of spatially varied values for the coefficients in the Z-R law, which are supposed to reduce uncertainty in radar rainfall estimates.

\section{Material and methods}

\subsection{Study area}

The study region is an area located in the center of Mexico, nearby the Mexico City, where a Cband radar known as Cerro Catedral is located along with the disdrometer network of the IIUNAM. As it is shown in Figure 1, the disdrometer network is less than $50 \mathrm{~km}$ away from the radar location (see black dots), the C-band radar is located about $40 \mathrm{~km} \mathrm{NW}$ of Mexico City (yellow pentagon in the figure) at an altitude of $3785 \mathrm{~m}$, and at the edge of the Valle de Mexico watershed (shown by the dark blue line). While the Mexico City area is illustrated by the red region.

\subsection{Methodology}

Due to its capabilities, i.e., a high temporal sampling resolution (here $1 \mathrm{~min}$ ), the identification of the type of precipitation, the compactness of the sensor, and its cost, Parsivel2 ${ }^{\circledR}$ (by OTT Hydromet) was chosen as the disdrometer to build this network by IIUNAM. Parsivel is a laser optical disdrometer [9] providing DSD measurements as well as integrated DSD coefficients, i.e., rain rate, radar reflectivity 
factor, and information on precipitation type. The instrument consists of a transmitter and a receiver separated by a $54 \mathrm{~cm} 2$ laser beam and it is sensitive to raindrop diameter ranging from 0.2 to $25 \mathrm{~mm}$ and rain rate from 0.001 to $1200 \mathrm{~mm} / \mathrm{h}$ (with accuracy for liquid measurement of $+/-5 \%$ ) [10].

On the other hand, the Cerro Catedral radar (by Sigmet/Vaisala technology) has Doppler, wich has single polarization, 1 degree of angular resolution and a maximum coverage of $300 \mathrm{~km}$. The radar measures reflectivity through three steps: surveillance (Plan Position Indicator (PPI) at elevation $-0.5^{\circ}$ or $0.5^{\circ}$ ), set of PPI scans at elevations 10 and 4 , with temporal resolution between 5 and $15 \mathrm{~min}$. The Mexican Weather Service supplied raw data from this radar for the years 2016 (complete) and 2017(until June). Currently, the radar only operates in the steps of surveillance with one sweep of the $0.5^{\circ}$ every $5 \mathrm{~min}$.

Regarding the analysis period, this was based on the availability of data from the disdrometers. The variability of the length of the data series between the stations is related to the start date of their operation (Aragón-09/01/16, Bosque Real-05/24/17, Coapa-12/13/16, Cuajimalpa-11/09/16, Dos Rios05/22/17, IIUNAM-01/01/16, Madin-08/31/16, Prepa 4-07/06/16, SACMEX-06/01/16, V. Hermosa10/0/16). This data was evaluated until August 23, 2017.

We fitted Z-R relationships using to the most widely implemented power-type function [5]:

$Z=a R^{b}$

where $\mathrm{Z}$ is in $\mathrm{mm}^{6} / \mathrm{m}^{3}, \mathrm{R}$ in $\mathrm{mm} / \mathrm{h}$, and a and $\mathrm{b}$ are coefficients which are commonly estimates by logarithmic linear regression (least squares fitting) between Z-R pairs. With regards to the data sets we make two considerations. The first one is related to frequency of data observation, because the disdrometer and radar data do not have the same observation frequency. Then, the disdrometer data series were re-arranged in ' $\mathrm{x}$ ' min (average data) for 5 and 10 min frequency.

The second one is about the threshold of data. For calibration, the Z-R relation needs at least two points by non-zero data in order to reduce bias to zero [11]. Many other researchers also suggest the application of a threshold $[12,13,14]$. Therefore, we considered $\mathrm{R}=0.5 \mathrm{~mm} / \mathrm{h}$ as the threshold.

In the first place, the Z-R relation is fitted for the whole data series. Next, the Z-R relations are found separately classifying the dataset in relation to the type of rainfall. These processes are applied for original data series (frequency $=1 \mathrm{~min}$ ) and average data series $(5$ and $10 \mathrm{~min})$. We tested three methods: dBZ-classification [15], R-classification [6] and Do/R [14], which categorize rain in ST, T or C (stratiform, transition rain or convective). The first and second method classify rain only in ST and C, a simple threshold technique, reflectivity and rain rate value of $38 \mathrm{dBZ}$ and $10 \mathrm{~mm} / \mathrm{h}$ are used as the thresholds to distinguish the precipitation type, such that minutes having values above this threshold are assumed to be $\mathrm{C}$ while those below are assumed ST, respectively. The last method considers that rain presents a different behavior between ST and C stage, and then include the T stage. For this, the relation between Do (the diameter of the drop) and $\mathrm{R}$ (rain rate) to classify rain according flow threshold is represented as: $\mathrm{Do} / \mathrm{R}>0.5=\mathrm{ST}, 0.1<\mathrm{Do} / \mathrm{R}<0.5=\mathrm{T}$ and $\mathrm{Do} / \mathrm{R}<0.1=\mathrm{C}$. About this context, it is important to mention that there are other methodologies to classify rain with a disdrometer data, for example [13] which is very well know, but we not used it because only is possible apply it per event, whereas consider subjectively the behavior of the many variables.

To evaluate the Z-R relations, these were applied using the reflectivity data of Cerro Catedral radar for a single event. The reflectivity raw data was corrected by the removal of clutter and attenuation correction using the Gabella filter [16] and Kraemer method [17] combined with restrictions prosed by [18], respectively. Then, it was assessed comparing the estimated rain rate with the disdrometer measurement, through the flowing statistical metrics: Pearson's correlation coefficient (r), determination coefficient (R2), Nash-Sutcliffe's efficiency coefficient (NS) and Mean Absolut Error (MAE). 


\section{Results and discussion}

Table 1 summarizes the values for the coefficients $(a, b)$ estimated, the determination coefficient $\left(\mathrm{R}^{2}\right)$ and the number of data pairs used (n) using the whole dataset at each location for three different time intervals of 1, 5 and $10 \mathrm{~min}$. Indeed, values for these coefficients are very close to those proposed by [5]. Notably, the determination coefficient (R2) and coefficient a, show a reduction when increasing the time interval of the dataset ( 5 and $10 \mathrm{~min}$ ). Certainly, results here shown, indicate a different trend in comparison to that reported by [12], however, this difference may be explained by the difference in climates and study region [6].

To give an example, Figure 2 (top panel) shows the variability Z-R relations when using the whole data series from the for the IIUNAM station using different temporal and (bottom panel) an example of the variability coefficients in function of the rain classification method (for 1 min dataset).Table 2 summarizes the values for the coefficients $(a, b)$ estimated using the all rain classification methods at each particular location for different time intervals of 1,5 and $10 \mathrm{~min}$. With regards to the coefficients of the fitted power-law to these data series, the a values are shown to be in order $\mathrm{C}<(\mathrm{T})<\mathrm{ST}$ for most stations and methods (like reported in [6]) and sometimes the opposite (like reported in [13]).

The above results evidence that the coefficients $a$ and $b$ show great variability between stations (spatial variation) and method of classification of the rain type. Thus, it demonstrates the need for setting specific coefficients for each study area. To evaluate the applicability of the coefficients obtained for quantitative estimation rain, especially those derived from rain classification methods, the reflectivity from the C-band radar was used in the event that occurred at the Coapa station on 05/29/2017. This event occurred between $18 \mathrm{~h} 32 \mathrm{~min}$ at $21 \mathrm{~h} 42 \mathrm{~min}$ (local time) and registered a maximum rain rate of $246.98 \mathrm{~mm} / \mathrm{h}$ at $16 \mathrm{~h} 20 \mathrm{~min}$. The period of the event was defined considering the criteria of [19]. Figure 3 illustrates radar reflectivity data during the peak of the event and the spatial variation of the rain rate recorded by the disdrometers.

First, the reflectivity data recorded by radar was evaluated. With regards to the disdrometer data series used for this comparison, we consider the data series re-arranged in min 5 with the application of moving average data. Regarding the radar data, we consider the value to the nearest pixel of the station and the average of the 9 pixels closest.

The comparison (Figure 4 (left)) shows that the radar does not measure the reflectivity very well quantitatively registered on the earth's surface (pixel $1 \mathrm{r}=0.38$, average pixels $\mathrm{r}=0.66$ ). The Catedral radar is located on top the mountain (3785 m), approximately $1500 \mathrm{~m}$ above Mexico City, so it does not interfere with local development. To improve the correlation between surface and remote data, a linear regression correction was applied between radar data and disdrometer original data $(1 \mathrm{~min})$, to consider high-resolution data. It reduced the distance between values but did not reach the exact values (i.e. average pixels: NS from -5.04 to 0.43 ).

The estimated rain rate based on radar reflectivity (original and corrected), considering the different coefficients previously obtained, did not show a perfect fit with the values observed by the Coapa disdrometer. The values of the statistical metrics are shown in Figure 5.

The coefficients $(a, b)$ obtained by rain classification with Do/R method and data series aggregated in $5 \mathrm{~min}$ provided a better estimate of the rain rate, especially with the use of the average pixels correction data series (Figure 4 (right)). To this case, we obtained following statistics: $r=0.80, R^{2}=$ $0.64, \mathrm{NS}=0.55$ and $\mathrm{MAE}=21.34 \mathrm{~mm} / \mathrm{h}$.

\section{Conclusions}

These results do indicate the need of a careful investigation on how to define an adequate Z-R relationship for this weather radar. It is acknowledged that different methods provide a variation in the 
coefficients used in the Z-R relationship with the same data and also presented variability between stations. Regarding Z-R relationship with classifying the rain through the three methods mentioned, there was an increase in variation of the coefficients between stations. The first hypothesis for this behaviour is the inadequate thresholds of the methods for the climate of this region, especially for Do/ $\mathrm{R}$ method. The second is related the amount of data used for this classification, that did not permit to obtain a stable Z-R relation.

Concerning radar reflectivity data, the evaluation indicates that the values do not correspond quantitatively to those recorded on the earth's surface, but it can represent the variances in most of the period. Consequently, the rain estimated from these data did not result in a good fit. We conclude that a correction with simple linear regression does not show sufficient to correct radar information, so there is more to investigate.

Regarding the Coapa event, one the hypothesis for these results is that the storm developed in a low layer of the atmosphere, that is, the storm was deeply convective. It is because we also investigated the registers made the by GPM satellite (IMERG v5) and the values (max. $\approx 4 \mathrm{~mm} / \mathrm{h}$ ) are similar to the ones estimated with any of the coefficients by the radar original data. The non-existence of the PPI scans at few elevations from Catedral radar prevents the analysis of the vertical development of the storm. Other study about this radar and area also found inconsistency between radar estimated and measured rain, but instead used rain gauge of the tipping-bucket and Z-R relationship fit with reflectivity radar data [20].

As for the continuation of this study, other methods will be tested to correct the attenuation and remove clutter from the raw radar data, with other thresholds to classify rain measurement methods to adjust the Z-R relationship, and apply a method of assimilation of remote (radar) and surface (gauge) [21] data.
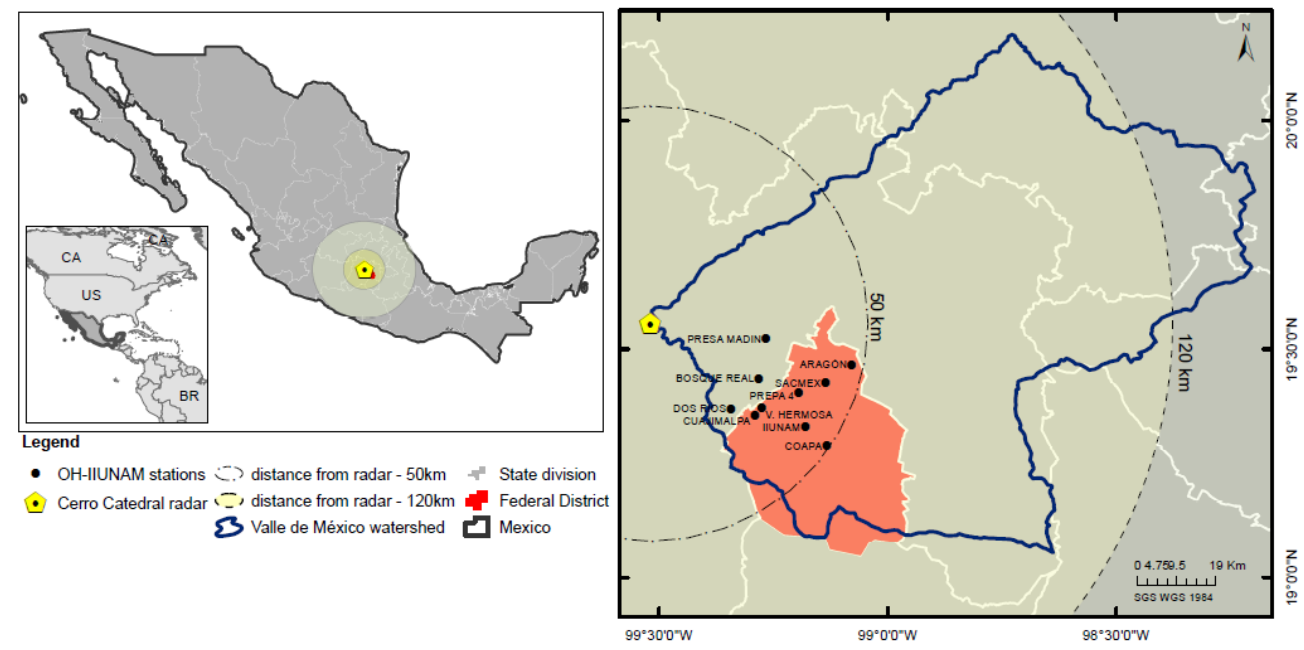

Figure 1: Location of the disdrometers network and area covered by the Cerro Catedral radar, Mexico. 
Z-R Law for Quantitative Rainfall Estimation Using a ... R. K. Mocva-Kurek and A. Pedrozo-Acuña
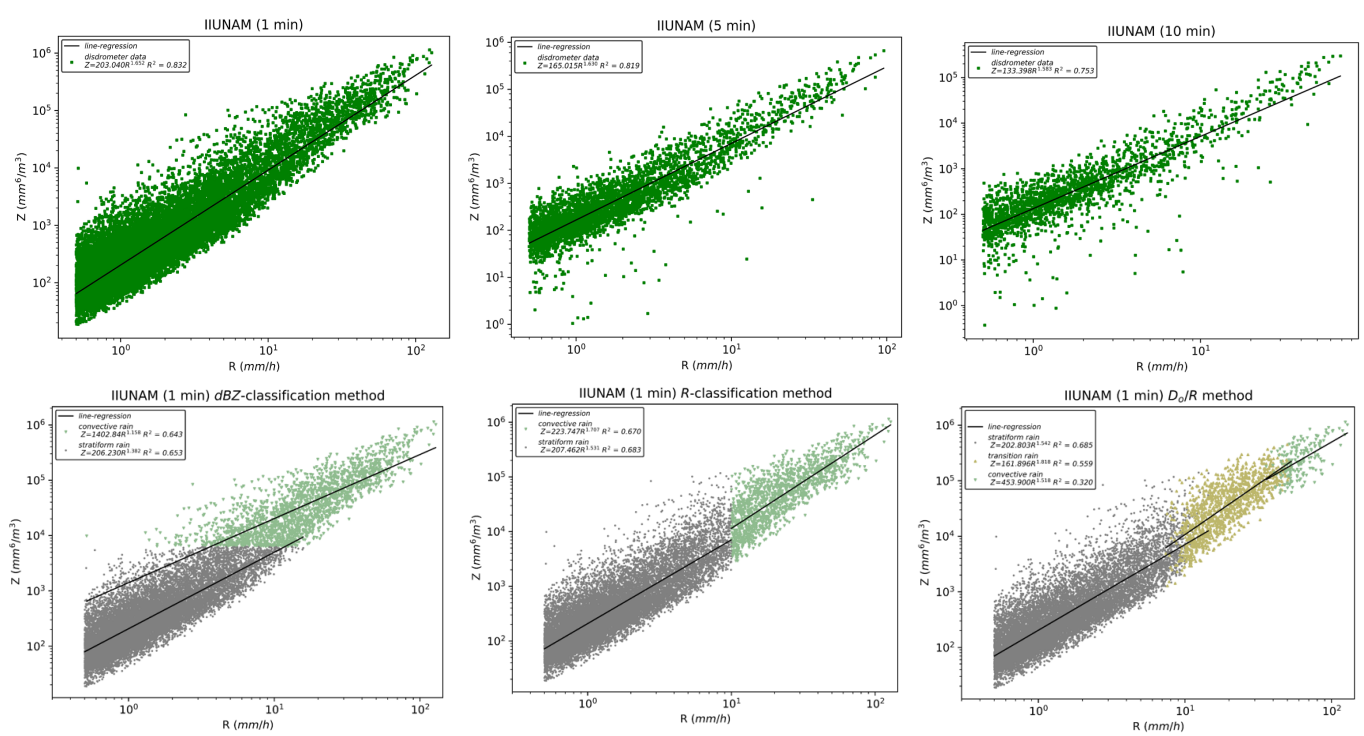

Figure 2: Top panel: Scatter plot on logarithmic scale of $Z$ versus $R$ and $Z-R$ relationships (IUNAM) (1, 5 and $10 \mathrm{~min}$ ); bottom panel: Scatter plot for the $1 \mathrm{~min}$ dataset illustrating the type of measured rainfall

\begin{tabular}{|c|c|c|c|c|c|c|c|c|c|c|c|}
\hline & Aragón & $\begin{array}{c}\text { Bosque } \\
\text { Real }\end{array}$ & Coapa & Cuajimalpa & Dos Rios & IIUNAM & Madin & Prepa 4 & SACMEX & $\begin{array}{c}\text { V. } \\
\text { Hermosa } \\
\end{array}$ & average \\
\hline \multicolumn{12}{|c|}{$\Delta \mathrm{t} 1$ minute } \\
\hline $\mathrm{a}$ & 211.45 & 191.65 & 224.51 & 174.34 & 183.39 & 203.04 & 182.52 & 205.61 & 219.57 & 168.35 & \multirow{4}{*}{$\begin{array}{c}196.44 \\
1.64\end{array}$} \\
\hline b & 1.62 & 1.63 & 1.64 & 1.65 & 1.62 & 1.65 & 1.59 & 1.65 & 1.65 & 1.67 & \\
\hline $\begin{array}{l}\mathrm{K} \\
2\end{array}$ & 0.80 & 0.86 & 0.85 & 0.82 & 0.83 & 0.83 & 0.76 & 0.82 & 0.83 & 0.81 & \\
\hline$n$ & 8430 & 4870 & 5234 & 7088 & 6556 & 18020 & 6596 & 10271 & 12218 & 9458 & \\
\hline \multicolumn{12}{|c|}{$\Delta \mathrm{t} 5$ minute } \\
\hline $\mathrm{a}$ & 175.08 & 153.22 & 167.44 & 140.16 & 150.87 & 165.02 & 159.81 & 164.84 & 172.26 & 137.59 & \multirow{4}{*}{$\begin{array}{c}158.63 \\
1.63\end{array}$} \\
\hline b & 1.60 & 1.63 & 1.62 & 1.65 & 1.60 & 1.63 & 1.58 & 1.64 & 1.65 & 1.68 & \\
\hline $\begin{array}{l}\mathrm{R} \\
2\end{array}$ & 0.79 & 0.85 & 0.80 & 0.83 & 0.80 & 0.82 & 0.77 & 0.80 & 0.82 & 0.83 & \\
\hline$n$ & 1762 & 1013 & 1114 & 1608 & 1470 & 3734 & 1409 & 2166 & 2549 & 1974 & \\
\hline \multicolumn{12}{|c|}{$\Delta \mathrm{t} 10$ minute } \\
\hline $\mathrm{a}$ & 138.00 & 110.87 & 133.53 & 111.50 & 125.22 & 133.40 & 131.47 & 128.95 & 137.15 & 107.88 & \multirow{4}{*}{$\begin{array}{c}125.80 \\
1.60\end{array}$} \\
\hline b & 1.59 & 1.60 & 1.59 & 1.62 & 1.56 & 1.58 & 1.58 & 1.62 & 1.62 & 1.68 & \\
\hline $\begin{array}{l}1 \\
2\end{array}$ & 0.69 & 0.74 & 0.75 & 0.77 & 0.73 & 0.75 & 0.70 & 0.73 & 0.76 & 0.77 & \\
\hline$n$ & 925 & 532 & 578 & 852 & 767 & 1959 & 715 & 1137 & 1328 & 1050 & \\
\hline
\end{tabular}

Table 1: Z-R relationships for the all disdrometer data series $(\mathrm{R}>5 \mathrm{~mm} / \mathrm{h})$ from the 1,5 and $10 \mathrm{~min}$.

\begin{tabular}{|c|c|c|c|c|c|c|c|c|c|c|c|}
\hline & & Aragón & Bosque Real & Coapa & Cuajimalpa & Dos Rios & IIUNAM & Madin & Prepa 4 & Sacmex & $\begin{array}{c}\text { V. } \\
\text { Hermosa }\end{array}$ \\
\hline & & \multicolumn{10}{|c|}{$\Delta \mathrm{t} 1 \mathrm{minute}$} \\
\hline \multirow{2}{*}{ ST } & $\mathrm{a}$ & 215.74 & 196.75 & 222.90 & 179.63 & 186.30 & 206.23 & 185.71 & 209.29 & 221.80 & 173.69 \\
\hline & $\mathrm{b}$ & 1.37 & 1.33 & 1.36 & 1.36 & 1.41 & 1.38 & 1.36 & 1.40 & 1.40 & 1.39 \\
\hline \multirow{3}{*}{ है } & $\bar{a}$ & 1772.53 & 1274.28 & 1842.07 & 1620.53 & 1781.31 & 1402.84 & 1893.02 & 1447.03 & 1482.76 & 1480.39 \\
\hline & $\mathrm{b}$ & 1.08 & 1.16 & 1.08 & 1.05 & 0.98 & 1.16 & 1.06 & 1.12 & 1.14 & 1.11 \\
\hline & & \multicolumn{10}{|c|}{$\Delta \mathrm{t} 5$ minute } \\
\hline \multirow{2}{*}{$\mathrm{ST}$} & $\bar{a}$ & 179.42 & 159.41 & 169.73 & 146.48 & 154.73 & 169.36 & 163.19 & 169.58 & 175.79 & 142.27 \\
\hline & $\mathrm{b}$ & 1.40 & 1.36 & 1.33 & 1.42 & 1.42 & 1.40 & 1.39 & 1.41 & 1.45 & 1.47 \\
\hline \multirow[b]{2}{*}{ C } & $\mathrm{a}$ & 957.57 & 616.97 & 1046.35 & 838.53 & 669.16 & 635.50 & 862.52 & 909.33 & 892.76 & 811.63 \\
\hline & $\mathrm{b}$ & 1.21 & 1.33 & 1.17 & 1.22 & 1.26 & 1.34 & 1.28 & 1.22 & 1.24 & 1.24 \\
\hline$\hat{\alpha}$ & & \multicolumn{10}{|c|}{$\Delta \mathrm{t} 10$ minute } \\
\hline \multirow{2}{*}{ ST } & $\mathrm{a}$ & 141.49 & 116.71 & 137.99 & 117.18 & 127.84 & 137.48 & 135.05 & 133.06 & 140.68 & 110.74 \\
\hline & $\mathrm{b}$ & 1.39 & 1.34 & 1.28 & 1.37 & 1.42 & 1.35 & 1.40 & 1.41 & 1.44 & 1.51 \\
\hline \multirow{2}{*}{$\mathrm{C}$} & $\bar{a}$ & 1118.37 & 450.93 & 748.70 & 763.95 & 1046.01 & 572.77 & 627.16 & 712.95 & 679.27 & 851.50 \\
\hline & $\mathrm{b}$ & 1.10 & 1.41 & 1.24 & 1.22 & 1.02 & 1.32 & 1.41 & 1.24 & 1.26 & 1.16 \\
\hline
\end{tabular}


Z-R Law for Quantitative Rainfall Estimation Using a ... R. K. Mocva-Kurek and A. Pedrozo-Acuña

\begin{tabular}{|c|c|c|c|c|c|c|c|c|c|c|c|c|}
\hline & & & \multicolumn{10}{|c|}{$\Delta \mathrm{t} 1$ minute } \\
\hline \multirow{2}{*}{\multicolumn{2}{|c|}{ ST }} & $\mathrm{a}$ & 216.18 & 198.02 & 226.00 & 179.95 & 187.11 & 207.46 & 186.03 & 210.03 & 223.55 & 173.55 \\
\hline & & $\mathrm{b}$ & 1.51 & 1.47 & 1.56 & 1.53 & 1.53 & 1.53 & 1.50 & 1.55 & 1.57 & 1.55 \\
\hline \multirow{3}{*}{$\bar{c}$} & & $\mathrm{a}$ & 273.01 & 217.82 & 566.10 & 210.60 & 65.65 & 223.75 & 76.89 & 137.08 & 208.39 & 169.57 \\
\hline & $c$ & $\mathrm{~b}$ & 1.67 & 1.69 & 1.41 & 1.67 & 2.05 & 1.71 & 2.05 & 1.85 & 1.73 & 1.76 \\
\hline & & & \multicolumn{10}{|c|}{$\Delta \mathrm{t} 5$ minute } \\
\hline \multirow{2}{*}{\multicolumn{2}{|c|}{$\mathrm{ST}$}} & $\mathrm{a}$ & 178.62 & 158.85 & 169.15 & 145.07 & 154.00 & 168.57 & 162.18 & 168.22 & 175.59 & 140.89 \\
\hline & & $\mathrm{b}$ & 1.49 & 1.46 & 1.53 & 1.53 & 1.51 & 1.52 & 1.51 & 1.55 & 1.56 & 1.59 \\
\hline \multirow{3}{*}{\multicolumn{2}{|c|}{$\mathrm{C}$}} & $\mathrm{a}$ & 235.52 & 155.65 & 354.17 & 121.29 & 40.86 & 114.07 & 69.18 & 87.46 & 157.52 & 86.10 \\
\hline & & $\mathrm{b}$ & 1.64 & 1.73 & 1.45 & 1.79 & 2.14 & 1.83 & 2.01 & 1.92 & 1.75 & 1.90 \\
\hline & & & \multicolumn{10}{|c|}{$\Delta \mathrm{t} 10$ minute } \\
\hline \multirow{2}{*}{\multicolumn{2}{|c|}{ ST }} & $\mathrm{a}$ & 141.05 & 114.42 & 136.57 & 115.86 & 127.57 & 136.63 & 133.23 & 131.81 & 140.05 & 110.08 \\
\hline & & $\mathrm{b}$ & 1.46 & 1.48 & 1.44 & 1.47 & 1.47 & 1.46 & 1.53 & 1.53 & 1.52 & 1.59 \\
\hline \multirow{3}{*}{\multicolumn{2}{|c|}{$\mathrm{C}$}} & $\mathrm{a}$ & 339.76 & 22.99 & 145.98 & 136.16 & 62.93 & 49.63 & 12.38 & 21.37 & 80.29 & 70.84 \\
\hline & & $\mathrm{b}$ & 1.46 & 2.19 & 1.64 & 1.68 & 1.91 & 2.01 & 2.49 & 2.29 & 1.88 & 1.89 \\
\hline & & & \multicolumn{10}{|c|}{$\Delta \mathrm{t} 1$ minute } \\
\hline \multirow{2}{*}{\multicolumn{2}{|c|}{ ST }} & $\mathrm{a}$ & 216.54 & 197.45 & 225.55 & 179.25 & 186.72 & 202.80 & 185.97 & 210.09 & 223.57 & 173.42 \\
\hline & & $\mathrm{b}$ & 1.48 & 1.49 & 1.58 & 1.55 & 1.54 & 1.54 & 1.50 & 1.55 & 1.56 & 1.55 \\
\hline \multirow{2}{*}{\multicolumn{2}{|c|}{$\mathrm{T}$}} & $\mathrm{a}$ & 410.27 & 137.38 & 267.45 & 152.01 & 111.13 & 161.90 & 46.23 & 168.35 & 202.27 & 171.25 \\
\hline & & $\mathrm{b}$ & 1.53 & 1.84 & 1.65 & 1.77 & 1.87 & 1.82 & 2.24 & 1.78 & 1.75 & 1.75 \\
\hline \multirow{3}{*}{\multicolumn{2}{|c|}{$\mathrm{C}$}} & $\mathrm{a}$ & 8034.44 & 409.14 & 1192.26 & 1036.08 & 88.05 & 453.90 & 289.00 & 906.61 & 937.29 & 1294.39 \\
\hline & & $\mathrm{b}$ & 0.82 & 1.53 & 1.23 & 1.29 & 1.87 & 1.52 & 1.70 & 1.39 & 1.36 & 1.30 \\
\hline & & & \multicolumn{10}{|c|}{$\Delta \mathrm{t} 5$ minute } \\
\hline \multirow{2}{*}{\multicolumn{2}{|c|}{$\begin{array}{l}\tau \\
\mathrm{c} \\
\mathrm{c}\end{array}$}} & $\mathrm{a}$ & 179.53 & 159.55 & 169.45 & 144.47 & - & 166.17 & 162.25 & 168.20 & 175.89 & 140.96 \\
\hline & & $\mathrm{b}$ & 1.48 & 1.47 & 1.54 & 1.55 & - & 1.52 & 1.51 & 1.56 & 1.58 & 1.59 \\
\hline \multirow{2}{*}{\multicolumn{2}{|c|}{$\mathrm{T}$}} & $\bar{a}$ & 29.23 & 23.43 & 32.38 & 46.11 & - & 77.14 & 89.29 & 66.28 & 28.29 & 94.56 \\
\hline & & $\mathrm{b}$ & 2.43 & 2.36 & 2.28 & 2.11 & - & 1.96 & 1.92 & 2.02 & 2.32 & 1.86 \\
\hline \multirow{3}{*}{\multicolumn{2}{|c|}{ C }} & $\mathrm{a}$ & 0.00 & 355.90 & 0.14 & 10.14 & - & 0.16 & 1.10 & 0.00 & 229.29 & 21768.20 \\
\hline & & $\mathrm{b}$ & 1.01 & 1.54 & 3.08 & 2.31 & - & 3.45 & 2.99 & 6.72 & 1.65 & 0.62 \\
\hline & & & \multicolumn{10}{|c|}{$\Delta \mathrm{t} 10$ minute } \\
\hline \multirow{2}{*}{\multicolumn{2}{|c|}{ ST }} & $\bar{a}$ & 142.13 & 116.03 & 136.43 & 115.00 & - & 134.49 & 133.16 & 131.49 & 141.21 & 109.61 \\
\hline & & $\mathrm{b}$ & 1.50 & 1.50 & 1.46 & 1.52 & - & 1.50 & 1.54 & 1.58 & 1.54 & 1.63 \\
\hline \multirow{2}{*}{\multicolumn{2}{|c|}{$\mathrm{T}$}} & $\bar{a}$ & 4.57 & 3.05 & 34.00 & 24.06 & - & 2.57 & 6.23 & 15.69 & 5.97 & 4.72 \\
\hline & & $\mathrm{b}$ & 2.93 & 2.86 & 2.14 & 2.22 & - & 2.96 & 2.77 & 2.39 & 2.76 & 2.81 \\
\hline \multirow{2}{*}{\multicolumn{2}{|c|}{$\mathrm{C}$}} & $\mathrm{a}$ & 0.00 & 7017.30 & 20323.81 & 0.24 & - & 0.00 & 0.00 & 0.00 & 324.51 & 0.02 \\
\hline & & $\mathrm{b}$ & 5.22 & 0.83 & 0.56 & 3.18 & - & 4.81 & 6.12 & 5.72 & 1.51 & 3.83 \\
\hline
\end{tabular}

Table 2: Z-R relationships for the all disdrometers data series $(\mathrm{R}>5 \mathrm{~mm} / \mathrm{h})$ according to the rain classification method for different temporal aggregation intervals (1,5 and $10 \mathrm{~min})$.

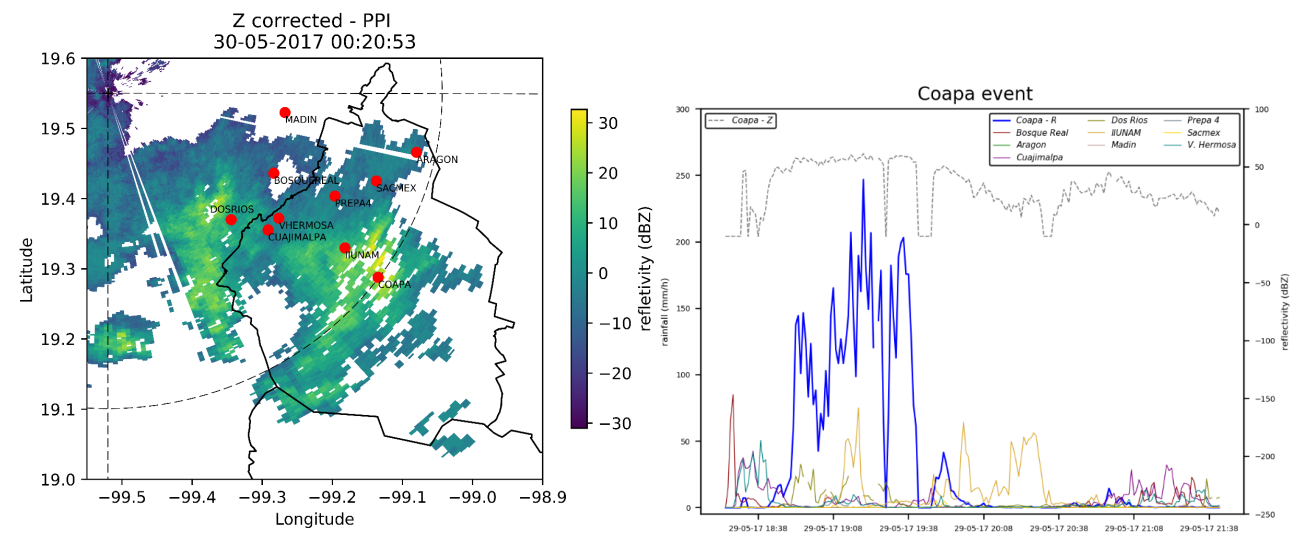

Figure 3: The distribution of the equivalent reflectivity factor (dBZ) from Cerro Catedral radar (left) and rain rate and reflectivity factor of the disdrometers (right) from Coapa event. 
Z-R Law for Quantitative Rainfall Estimation Using a ... R. K. Mocva-Kurek and A. Pedrozo-Acuña
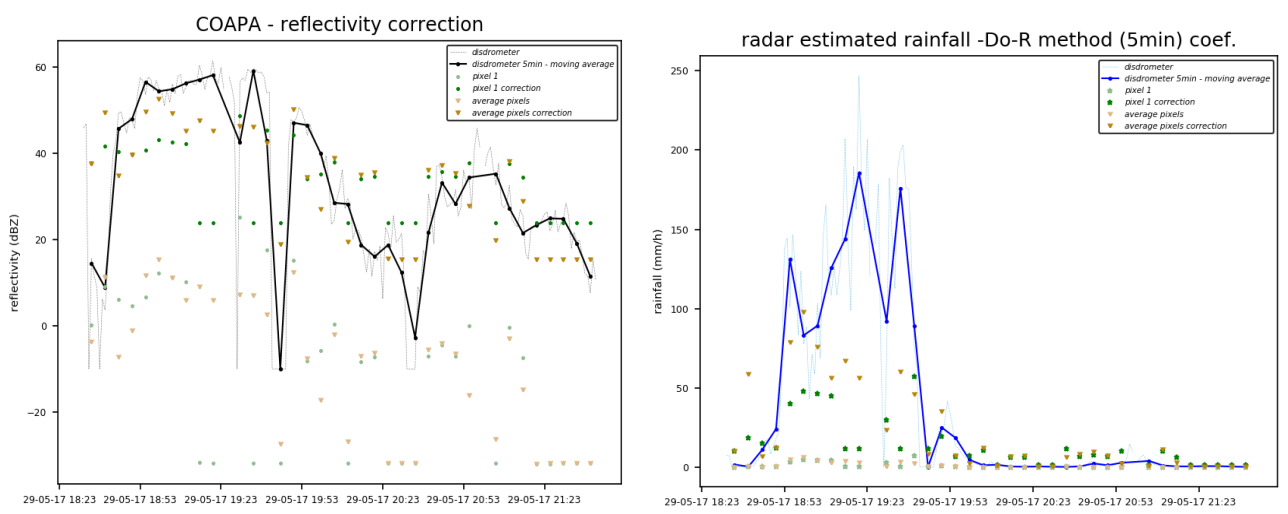

Figure 4: Comparison of the (left) reflectivity data registered by the Catedral (corrected) radar and the Coapa; and (right) rainfall data estimated by the reflectivity radar data (original and corrected) with the coefficients obtained by $\mathrm{Do} / \mathrm{R}$ method and data series aggregated in $5 \mathrm{~min}$.
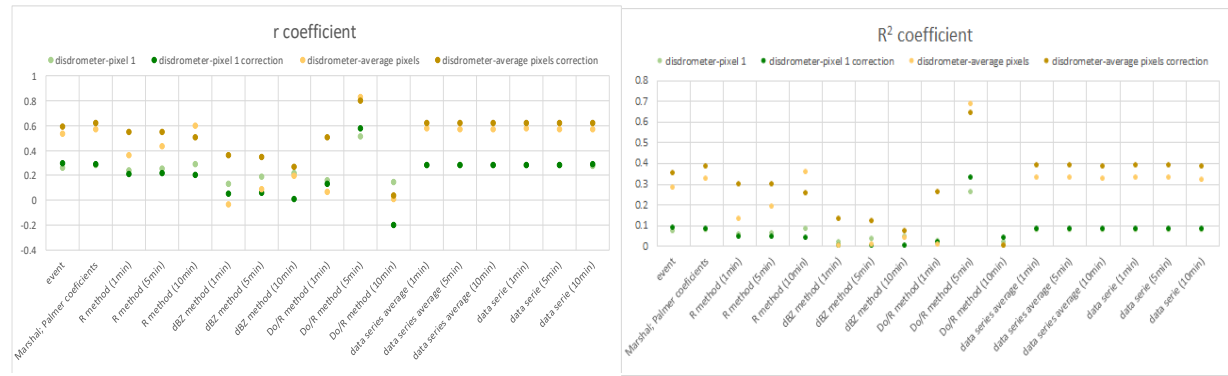

NS coefficient

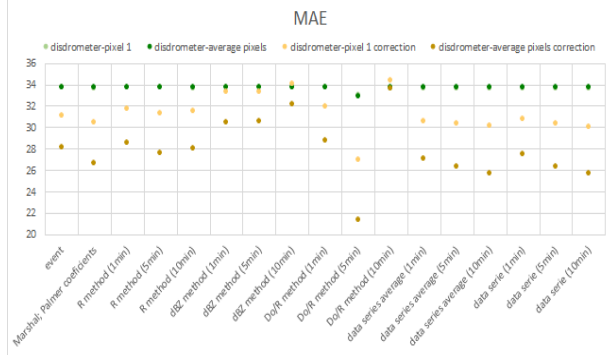

Figure 5: Pearson correlation coefficient (r), determination coefficient (R2), Nash-Sutcliffe efficiency coefficient (NS) and Mean Absolut Error (MAE) of the estimated rain rate with different coefficients adjusted previous for the Z-R relationship.

\section{References}

[1]M. A. Rico-Ramirez, S. Liguori, A. N. A. Schellart, Quantifying radar-rainfall uncertainties in urban drainage flow modelling. Journal of Hydrology, vol 528 (2015) 17-28.

[2]A. Berne, G. Delrieu, J.-D. Creutin, C, ObledTemporal and spatial resolution of rainfall measurements required for urban hydrology J. Hydrol., 299 (3-4) (2004) 166-179.

[3]J.-M. Faures, D. Goodrich, D.A. Woolhiser, S. SorooshianImpact of small-scale spatial rainfall variability on runoff modeling J. Hydrol., 173 (1995) 309-326

[4]P. Licznar, W. F. Krajewski, Precipitation Type Specific Radar Reflectivity-rain Rate Relationships for Warsaw, Poland, Acta Geophysica, 64(5) (2016) 1840-1857. 
Z-R Law for Quantitative Rainfall Estimation Using a ... R. K. Mocva-Kurek and A. Pedrozo-Acuña

[5] J. S. Marshall, W. M. Palmer, The distribution of raindrops with size, J. of Atmos. Sci. 5 (1948) $165-166$.

[6] A. Nzeukou, H. Sauvageot, A. D. Ochou, C. M. F. Kebe, Raindrop Size Distribution and Radar Parameters at Cape Verde, Journal of Applied Meteorology 43(1) (2004) 90-105.

[7] J. A. Smith, W. F. Krajewski, A modeling study of rainfall rate-reflectivity relationships, Water Resour. Res., 29(8) (1993) 2505-2514.

[8] N. Yu, Précipitations méditerranéennes intenses - Characterisation microphysique et dynamique dans l'atmosphère et impacts au sol, thèse Université Joseph Fourier, Grenoble, France, (2012).

[9] M. Löffler-Mang, J. Joss, An optical disdrometer for measuring size and velocity of hydrometeors, J. Atmos. Oceanic Technol., 17(2) (2000) 130-139.

[10] OTT. Operating instructions. Present Weather Sensor OTT Parsilvel ${ }^{2}$. (2016)

[11] L. Alfieri, P. Claps, F. Laio, Time-dependent Z-R relationships for estimating rainfall fields from radar measurements, Natural Hazards and EarthSystem Science 10(1) (2010) 149-158.

[12] B. Chapon, G. Delrieu, M. Gosset, B. Boudevillain, Variability of rain drop size distribution and its effect on the Z-R relationship: A case study for intense Mediterranean rainfall, Atmospheric Research 87(1) (2008) 52-65.

[13] D. Atlas, C. W. Ulbrich, F. D. Marks, E. Amitai, C. R. Williams, Systematic variation of drop size and radar-rainfall relations, Journal of Geophysical Research: Atmospheres, 104(D6) (1999) 61556169.

[14] T. N. Rao, N. V. P. Kirankumar, B. Radhakrishna, D. N. Rao, K. Nakamura, Classification of Tropical Precipitating Systems Using Wind Profiler Spectral Moments. Part I: Algorithm Description and Validation, Journal of Atmospheric and Oceanic Technology 25(6) (2008) 884-897.

[15] J. F. Gamache, A. R. Houze, Mesoscale air motions associated with a tropical squall line, Monthly Weather Review 110 (1982) 118-135.

[16] M. Gabella, R. Notarpietro. Ground clutter characterization and elimination in mountainous terrain. In Use of radar observations in hydrological and NWP models, (2002) 305-311.

[17] S. Kraemer, H. R. Verworn. Improved C-band radar data processing for real time control of urban drainage systems. 11th International Conference on Urban Drainage, Edinburgh, Scotland, UK, (2008).

[18] S. Jacobi, M. Heistermann. Benchmarking attenuation correction procedures for six years of single-polarised c-band weather radar observations in south-west germany. Geomat. Nat. Haz. Risk., 7:6, (2016) 1785-1799.

[19] A. Tokay, W. Petersen, P. Gatlin, M. Wingo. Comparison of Raindrop Size Distribution Measurements by Collocated Disdrometers. Journal of Atmospheric and Oceanic Technology, 30 (8), (2013) 1672-1690.

[20] B. Méndez Antonio. Applicación Hidrológica de los Radares Meteorológicos. Thesis Enginier Faculty, Univeridad Nacional Autónoma de México (2005).

[21] E. Goudenhoofdt and L. Delobbe. Evaluation of radar-gauge merging methods for quantitative precipitation estimates. Hydrology and Earth System Sciences, 13(2) (2009) 195-203. 